\title{
RESOLUTIONS ADOPTED AT THE ANNUAL MEETING, OCTOBER $1949^{1}$
}

1. Whereas it is considered highly desirable that the Executive Council of the C.S.F.E. should be at all times in close touch with the thinking and opinions of members throughout Canada, and

WHEREAS it is considered that Section meetings and activities provide the right and proper sounding board for the development and airing of opinions, therefore

BE IT RESOLVED that each Section forward promptly to the Secretary of the C.S.F.E. a copy of the minutes of each Section meeting and of any papers read at such meetings, and it is recommended that within the limitations of the time available, the Secretary circulate to the Sections and to the Editorial Board of the Forestry Chronicle suitable digests of pertinent material received.

2. WherEAs the need for continuously improved forest management for sustained yield is evident; and

WHEREAS representatives of the industry and others have emphasized that insecurity of tenure, and in some cases taxation policies, tend to hamper sustained yield management; therefore

Be IT RESOLVED that the General Executive request all Sections to make special studies during the coming year on:

(a) Systems of tenure of forest land in Canada, the United States, and any other countries whose experience may be deemed useful, with a view to discovering the merits and demerits of each.

(b) The scientific principles of assessment and taxation which apply to forest properties, to determine the rightful amount which such properties should contribute to the public revenues.

(c) Systems of public control of operations on forest properties by private owners, lessees, etc., in use in Canada and other countries.

3. RESOLVED that the General Executive of the Society be requested to take the required action to inaugurate a consistent drive in all Sections for new members and to establish the office of Secretary-Treasurer on a full-time basis as soon as the cost can be covered in the Society budget.

4. WHEREAS there are in Canada extensive areas of unproductive forest land adjacent to organized communities; and

WHEREAS these areas are potentially important to the future economy of Canada; and the results of forestry practice within them would be apparent to the general public;

BE IT RESOLVED that the General Executive of the Society arrange, if possible, for a half-day session of the next annual meeting of the C.S.F.E. devoted to the discussion of the problems affecting the proper management of these areas.

5. WHEREAS the Canadian Society of Forest Engineers, as a national body of Professional Foresters, has affirmed in its statement of policy that it strongly favours youth education in forest matters, and believes that there is still much room for improvement in this field across this Dominion; and

1. The Resolution Committee consisted of W. A. E. Pepler, Chairman, G. W. I. Creighton, and Walter Giles. 
WHEREAS the Society recognizes that this improvement can best be accomplished by incorporating forestry material into the present courses of study in the schools rather than endeavouring to introduce further courses of study on an already crowded curriculum; therefore

BE IT RESOLVED that this Society reaffirm its interest in youth education on forestry matters and translate that affirmation into action by instructing its executive to appoint a sub-committee on forestry education in each province to stimulate the incorporation of forestry material into the present courses of study in schools.

6. WHEREAS it is desirable that every forester be encouraged to contribute to public education in forestry matters within the range of his social contacts; and

WHEREAS a classification of the ways and means of contacting different sections of the general public, if available to the individual forester, would greatly aid voluntary effort; therefore

BE IT RESOLVED that it be recommended to the Canadian Society of Forest Engineers that a committee on Public Instruction in Forestry be appointed with the following terms of reference:

(1) To study the social structure of and conditions in, different communities across Canada.

(2) To list the various media of social contact in each community.

(3) To list the various media of communication in each community.

(4) To indicate and discuss how individual foresters through their own voluntary efforts and in co-operation with others can carry the story of forestry to the public of Canada on a sustained basis.

7. WhereAs the maintenance of wildlife is a part of a full program of forest management; and

WHEREAS the distribution of cutting operations has a major influence on wildlife management; therefore

Be IT Resolved that the Canadian Society of Forest Engineers recommend to its members that in the drafting and execution of working plans, due attention be paid to sound principles of wildlife management.

8. WHEREAS there has been an increased interest in forestry matters on the part of the Dominion Government as evidenced by present legislation before the House of Commons; therefore

BE IT Resolved that the General Executive be requested to give consideration to forwarding to the Minister of Mines and Resources a communication expressing the interest and pleasure of the Canadian Society of Forest Engineers in this legislation.

9. Whereas the Canadian Forestry Association has recommended the calling of a Canadian Forestry Congress in 1950, and has clearly stated the needs for such a Congress in its brochure entitled "The Case for Forestry in Canada", itself an important contribution to public knowlledge on the status of Canada's forests; 
Be It Resolved that the Canadian Society of Forest Engineers assure the Canadian Forestry Association that it is entirely in accord with the calling of a Canadian Forestry Congress in 1950;

AND that the Society give consideration to possible courses of action designed to help bring about such a Congress and ensure its success.

10. WHEREAS improvement of woodlot management in Canada is a serious and urgent need; and

WHEREAS statistical data with reference to woodlots is very limited; therefore,

BE IT RESOLved that the Canadian Society of Forest Engineers request the Dominion Bureau of Statistics in the next census to collect and report information pertaining to woodlots, their condition, and their products, in greater detail than has been done in the past.

VOTE OF THANKS, ANNUAL MEETING, OCTOBER, 1949

The Society is greatly indebted to the Ontario Department of Lands and Forests and the Minister, the Honourable Harold R. Scott, for their gracious generosity in entertaining us so well at luncheon on the opening day.

Although our thanks were sincerely and ably expressed on that occasion, the Resolutions Committee recommends that the General Executive be requested to forward a more formal thank you in the proper terms expressed as a vote of thanks of the annual meeting.

We do not need to go into detail regarding the excellence of the arrangements and programme of the meeting we have attended. Your Resolutions Committee believes that we should express our appreciation of the magnificent work of Murray Morrison and his Committee in a formal vote of thanks, and that the General Executive should be requested to pass this on to them and also express our thanks to the speakers, the exhibitors, the hotel, the press, and others who have co-operated in the arrangements and programme.

\section{NEWS OF THE SECTIONS Maritimes}

Notes on Field Tour, Summer Meeting of New England Section, Society of American Foresters, to which Members of the Maritime Section, C.S.F.E., were invited, September 11-13, 1949.

1. The University of Maine Forest of Indian Townsbip

(a) A burn around 1920 on a mixed-softwood flat left a few large white pine seed trees. The pine seeded in well and on a slight knoll almost adequate stocking was produced. In 1932 the existing gaps were planted with red pine. Along the fringes of the burn on low, moister ground cedar reproduced well. The white pine showed scattered attacks of white pine blister rust but little weevilling. 